\title{
Technology and technical means for the quantitative assessment of dispersed characteristics of spray equipment for chemical plant protection
}

\author{
I.Y. Paremsky ${ }^{1}$, V.F. Fedorenko², E.G. Aristov², V.G. Selivanov' ${ }^{2, *}$, and N.N. Krakhovetsky ${ }^{2}$ \\ ${ }^{1}$ N.E. Bauman MSTU, Moscow, Russia \\ ${ }^{2}$ Rosinformagrotekh, Pravdinsky, Russia
}

\begin{abstract}
The purpose of the study is the development of new methods and technical means based on an innovative method of restoring the initial size of droplets, which will allow to determine the dispersed composition of spray droplets with high accuracy. The scientific novelty of the work is to develop an innovative test bench, the performance of which allow minimizing the impact of external influences on the process of measurement of the differential and integral characteristics of the spectrum of spray droplets, which will reduce the environmental load on biocinosis.
\end{abstract}

The creation of spray equipment designs having adjustable dispersion characteristics is the basis for the development of breakthrough, environmentally sound resource-saving technologies in the agricultural sector. They open a real opportunity to reduce the ecotoxicant load on agrocenoses and the human environment and significantly reduce the specific consumption of agrochemicals.

The solution to the problem of optimizing the functioning of sprayers, of course, should be based on the most accurate determination of the dispersion composition of spray droplets. It is this parameter that underlies all further calculations of the impact of the aerosol of the working fluid on the components of the process cycle. It is the fractional composition of the droplets of the working fluid that determines the efficiency of the spray equipment.

To determine these indicators, the following Interstate Standard applies:

GOST ISO 5682-1:2004 Equipment for crop protection - Spraying equipment - Part 1: Test methods for sprayer nozzles, Clause 7.6, Drop Size.

This paragraph provides a note:

"This test provides only minimal accuracy, so it will be revised to improve droplet sizing technology."

What may be the results of this minimum accuracy?

If the linear dimensions of the droplet have changed by $10 \%$, then this error will be $40 \%$ by weight, and with a $20 \%$ change in size, the error in determining the weight of the sprayed liquid (and, therefore, the application rate, concentration of the agent) will approach to $100 \%$.

* Corresponding author: fgnu@mail.ru 
An experimental study of fine dispersion liquid sprayers and the processes of formation of liquid droplet media is associated, for quite objective reasons, with a number of factors that seriously affect the accuracy of the results obtained. Moreover, the magnitude of the error can be very significant. Three main factors that have the greatest influence on the purity of the experiment are to be distinguished.

The first and most significant factor is a short lifetime of finely divided evaporating droplets. Depending on the temperature and humidity of the environment, the time for complete evaporation of small droplets (less than 30 microns in size) varies from fractions of a second to several seconds, and the time for relatively large droplets (more than 150 microns in size) varies up to tens of seconds. During the experiment, small droplets have time to completely evaporate, and large droplets are reduced in size. This greatly distorts the spectrum of spray droplets.

The second significant factor is the difference in the rate of gravitational deposition of droplets of various sizes. Due to this difference, the sedimentation of the droplets, i.e. the volume from which the droplets settle on the collector, will depend on the size of the droplets. At the same time, there is no need to talk about any representativeness of the sample. Without solving this issue, it is impossible to measure the true distribution of droplet size in the cross section of the spray torch.

And finally, there is the third factor. It is necessary to select an experimentally justified form of an analytical function approximating a curve obtained experimentally. Otherwise, all further calculations of the technologically effective operating modes of the spray equipment will be performed with a large error.

Now, the state of the issue for each of the three factors listed above should be discussed and prospects for research and development in these areas should be described.

Table 1 shows the numerical values of the evaporation time of droplets of different sizes under conditions of different temperatures and humidity of the environment.

Table 1. Evaporation time of the droplets.

\begin{tabular}{|c|c|c|c|}
\hline \multirow{2}{*}{ Droplet diameter $[\mu \mathrm{m}]$} & $\begin{array}{c}\mathrm{T}=20^{\circ} \mathrm{C} \\
\text { Humidity } 80 \%\end{array}$ & $\begin{array}{c}\mathrm{T}=25^{\circ} \mathrm{C} \\
\text { Humidity } 60 \%\end{array}$ & $\begin{array}{c}\mathrm{T}=30^{\circ} \mathrm{C} \\
\text { Humidity } 60 \%\end{array}$ \\
\cline { 2 - 4 } & \multicolumn{3}{|c|}{ Time of droplet complete evaporation [s] } \\
\hline 25 & 2 & 1.1 & 0.6 \\
\hline 50 & 7 & 3.7 & 2.1 \\
\hline 75 & 16 & 9 & 4.7 \\
\hline 100 & 50 & 30 & 14 \\
\hline
\end{tabular}

Table 2 shows the numerical values of the deposition rate of droplets of different sizes.

Table 2. Droplet Deposition Rate.

\begin{tabular}{|c|c|c|}
\hline Droplet diameter $[\mu \mathrm{m}]$ & Deposition rate $[\mathrm{cm} / \mathrm{s}]$ & $\begin{array}{c}\text { Deposition time } \\
\text { (at } 50 \mathrm{~cm} \text { fall height } \text { [s] }\end{array}$ \\
\hline 10 & 0.3 & 170 \\
\hline 20 & 1.2 & 43 \\
\hline 30 & 2.6 & 19 \\
\hline 40 & 4.7 & 11 \\
\hline 50 & 7.4 & 6.8 \\
\hline 60 & 11 & 4.7 \\
\hline 70 & 14 & 3.5 \\
\hline 80 & 19 & 2.6 \\
\hline 90 & 24 & 2.1 \\
\hline 100 & 29 & 1.7 \\
\hline
\end{tabular}


As it follows from the table, droplets smaller than 50 microns in size practically cannot reach the surface of the object to be protected, especially when it is considered that, during the deposition process, they continue to evaporate, their size decreases and, accordingly, the deposition rate decreases.

This paper proposes an innovative method for restoring the initial size of the droplets, which returns the initial appearance to the spectrum of the spray transformed as a result of interaction with the external environment [1].

The essence of the method is as follows. An information core is placed into every droplet at the time of its formation, which carries complete information about the initial parameters of the droplet. These parameters can be restored even in the case of complete evaporation of the droplet itself.

The hygroscopic $\mathrm{NaCl}$ inorganic compound was chosen as the "information core."

Relative humidity over a saturated solution of sodium chloride (and, therefore, at the surface of a dry crystal) is $78 \%$. If the humidity in the environment is below $78 \%$, a droplet of $\mathrm{NaCl}$ solution evaporates, while the salt crystal ("information core") is retained. If the relative humidity in the environment is above $78 \%$, moisture will begin to condense on the salt crystal, a droplet of solution will form, and it will grow until the humidity values in the environment and those at the surface of the droplet equalize. With a zero moisture gradient, the droplet size stabilizes.

It is characteristic that for sodium chloride, at a constant concentration of the solution, the relative humidity above it does not change with temperature in a wide enough range, which is very important when conducting an experiment of subsequent studies.

Droplets of a $10 \%$ sodium chloride solution, the relative humidity above which is $89 \%$, while being in the environment, where humidity is below this value, will evaporate. However, they will not disappear. There will be a "dry residue" in the form of $\mathrm{NaCl}$ crystals. If these crystals are placed in a hygrostat, in which the relative humidity is $89 \%$, the salt crystals will begin to be flooded and the solution droplets will grow until the moisture near their surface is $89 \%$, i.e. until the salt concentration in the drop becomes $10 \%$, which corresponds to the original droplet size.

The steps of the droplet size recovery process are as follows:

1 - dispersing drops of a $10 \% \mathrm{NaCl}$ solution and depositing them on the collector

2 - evaporation of droplets to a state of dry crystals

3 - transfer of the collector with $\mathrm{NaCl}$ crystals to the restoring chamber (hygrostat)

4 - condensation of vaporous moisture on a salt crystal

5 - restoration of the droplet to its original size.

The stages of sampling droplets ( 1 and 2$)$ and the stages of restoring the original size of a droplet (3, 4 and 5) can be separated in time for a sufficiently long period of time: sampling can be performed in the field, and the process of restoring and measuring the size of the restored droplets can be done through some time in the laboratory conditions.

The experimental studies on the restoration of the initial droplet size were performed according to the following method: a $10 \% \mathrm{NaCl}$ solution was sprayed, the droplets were deposited on a slide covered with a water-repellent layer (paraffin), thereafter the glass slide was placed in a hygrostat placed on a microscope stage.

Subsequently, the photographic record of the $\mathrm{NaCl}$ crystals and the process of condensation growth of solution droplets on them was performed.

Figures 1-4 show all the stages of droplet recovery to their original sizes. 

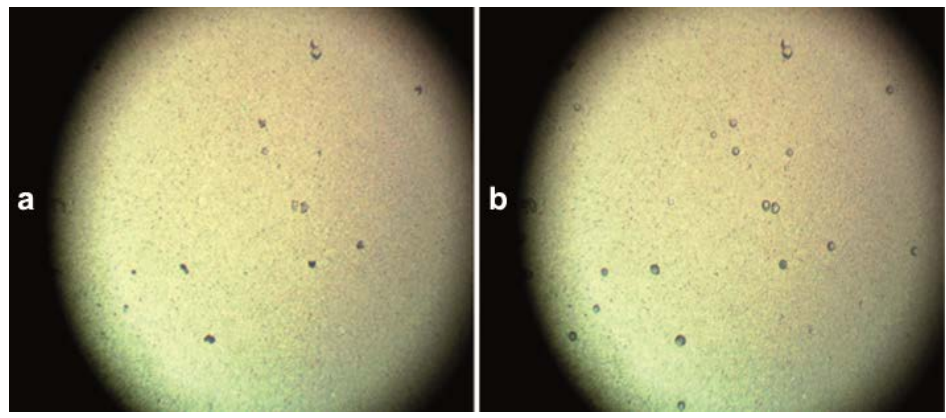

Fig. 1. Photo recording of the droplet recovery process: a - start of the process (dry crystals), $\mathrm{b}$ - stage of watering (the beginning of the growth of drops).

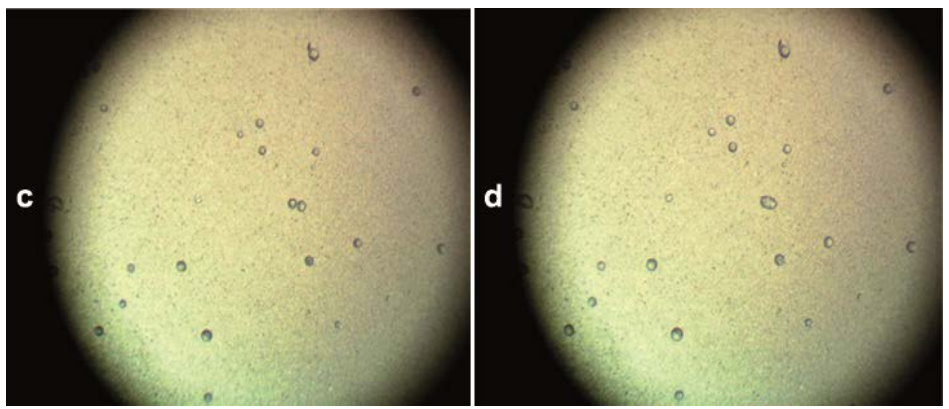

Fig. 2. Photo recording of the droplet recovery process: c, d - stage of intensive droplet growth.
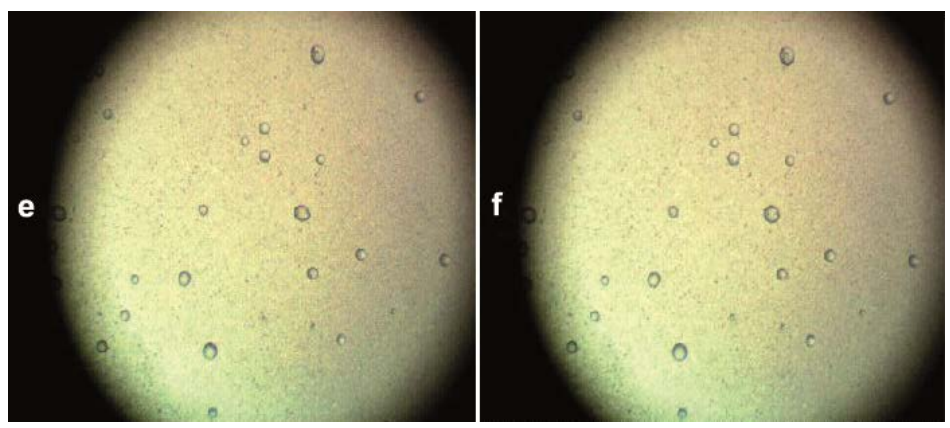

Fig. 3. Photo recording of the droplet recovery process: e, $\mathrm{f}$ - stage of deceleration of the condensation process.

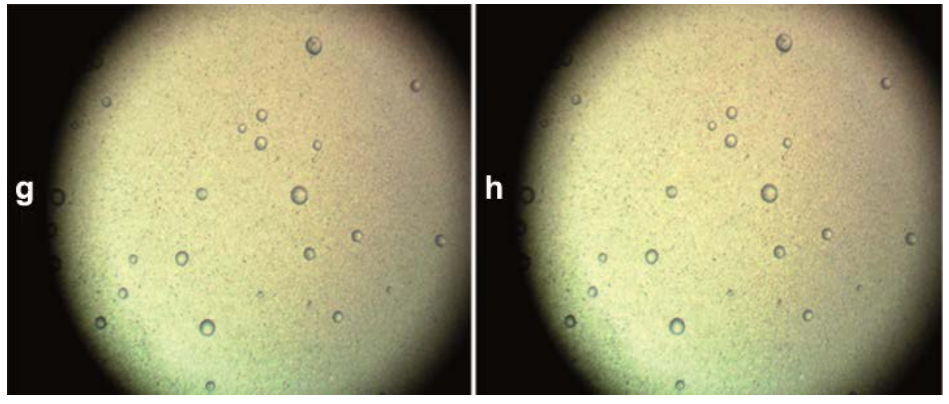

Fig. 4. Photo recording of the droplet recovery process: $\mathrm{g}, \mathrm{h}$ - stage of stabilization of droplet sizes (the time interval between images is 5 minutes: the droplet growth has stopped). 
To do this, we developed the design of and manufactured a test bench (an aerosol chamber), whose main purpose was to provide a representative sampling of the aerosol. This was achieved by the fact that the exposure time was determined not by the duration of holding the collector in the aerosol stream, but by the operating time of the nozzle itself, or rather by the time, during which the aerosol stream was supplied to the chamber. The feed time is controlled with a shutter. When the shutter is closed, the flow of the solution to the nozzle is turned on, and after the nuzzle has achieved the operation mode, the shutter opens, while opening access to the aerosol into the chamber, where the glass slides (collectors) are already installed. The collectors, after closing the shutter and turning off the nozzles, are kept in the chamber for a time sufficient to precipitate all the droplets. Then the samples are transferred to a restoring chamber and then processed under a microscope. In this case, not only the dispersed composition of the torch is determined, but also its "geography," i.e. distribution of droplets by size and quantity in different sections of the torch cross-section.

Thus, the aerosol chamber provides an aerosol sampling that is free from all kinds of errors associated with droplet evaporation, gravitational separation of droplets by size (deposition rate), inertia of sprayers, and droplet spraying upon impact on the chamber walls.

Since measuring the size of spray droplets under an optical microscope is an extremely time-consuming process, we have developed a computer program for the graphic processing of droplet images. After restoration of the size, the droplets were photographed with a digital camera mounted on the tube of the microscope. Each frame amounts 60 to 70 droplets. After receiving the required number of photos, the process of digital image processing began. The sizes of the droplets present in the frame were measured. After collecting the required sample size, the measurement results were grouped in intervals and transferred to a spreadsheet.

Table 3. Results of size measurement / calculated droplet concentration processing.

\begin{tabular}{|c|c|c|c|c|c|c|c|}
\hline \multicolumn{2}{|c|}{$\begin{array}{c}\text { Interval } \\
\text { boundaries }[\mu \mathrm{m}]\end{array}$} & \multicolumn{2}{|c|}{$\begin{array}{c}\text { Droplet } \\
\text { concentration in } \\
\text { the interval }\end{array}$} & \multirow{2}{*}{$\begin{array}{c}\text { Average value of } \\
\text { the droplet } \\
\text { diameter in the } \\
\text { interval } \\
D_{\text {avrg. }}[\mu \mathrm{m}]\end{array}$} & \multirow{2}{*}{$\begin{array}{c}\text { Average droplet } \\
\text { volume in the } \\
\text { interval }\end{array}$} & \multicolumn{2}{|c|}{$\begin{array}{l}\text { Total drolpet } \\
\text { volume in the } \\
\text { interval }\end{array}$} \\
\hline $\mathrm{d}_{\mathrm{i}}$ & $\mathrm{d}_{\mathrm{i}+1}$ & $\mathrm{n}_{\mathrm{i}}$ [pcs.] & $\%$ & & & $\sum \mathrm{V}_{\mathrm{i}}$ & $\%$ \\
\hline
\end{tabular}

The first three columns of the table contain data on measuring the size of the restored droplets using a graphic image processing program. Here, $d_{i}$ and $d_{i}+1$ are boundaries of the grouping interval, $n_{i}$ is a concentration of droplets in the interval, $n_{i} \%$ is a percentage of droplets in the interval, $d_{\text {avrg }}$ is an average diameter of a droplet in the interval, $V_{\text {avr }}$ is an average volume of droplets in the interval, $\sum V_{i}$ is a total volume of droplets in the interval, and $V_{i} \%$ is a percentage of the total droplet volume in the interval.

Comparative tests were conducted on two samples of nozzles manufactured by Lechler having the following specifications:

- Green nozzle: consumption is 0.4 liters / min at a pressure of 3 bar.

- Orange nozzle: consumption is 0.6 liter / $\mathrm{min}$ at a pressure of 3 bar.

Slides were laid in an aerosol chamber on the central platform of the sampler at a level of one meter away from the nozzle. Exposure time was 1 second. After blocking the aerosol stream, the collector was held for 40 minutes. During this time, all droplets larger than 30 microns in size managed to settle on the collector.

Based on the numerical values of the results of measuring the size of the droplets at their calculated concentration, the main indicators of the dispersion characteristics of the spray spectra of the orange and green nozzles were determined. Table 4 shows the calculation results. 
Table 4. Main indicators of the dispersion characteristics of the spray spectra of nozzles.

\begin{tabular}{|l|c|c|c|c|c|}
\hline Nozzle type & $\begin{array}{c}\text { Modal droplet } \\
\text { diameter }[\mu \mathrm{m}]\end{array}$ & $\begin{array}{c}\text { Average } \\
\text { (linear) } \\
\text { diameter }[\mu \mathrm{m}]\end{array}$ & $\begin{array}{c}\text { Average cubic } \\
(\text { volumetric) } \\
\text { diameter }\left[\mu \mathrm{m}^{3}\right]\end{array}$ & $\begin{array}{c}\text { Measured total } \\
\text { droplet volume } \\
{\left[\mathrm{dm}^{3} / \mathrm{ha}\right]}\end{array}$ & $\begin{array}{c}\text { Standard } \\
\text { deviation }\end{array}$ \\
\hline Orange & 110 & 125.9 & 157.7 & 181.9 & 65.3 \\
\hline Green & 110 & 122.8 & 150.8 & 114.0 & 60.0 \\
\hline
\end{tabular}

As it follows from the table, the main distribution indicators, such as modal, average, average cubic diameters, and standard deviation, for both nozzles coincide within the experimental error. The values of the total volume (weight) of the droplets differ. The volume of the settled drops of the orange nozzle is 1.6 times larger than the same parameter for the green nozzle. This ratio, within the limits of the experimental error, coincides with the proportion of consumption values for the nozzles studied.

Figure 5 shows graphs of the size distribution of spray droplet spectrum for orange and green nozzles. A comparison of the graphic representations of the spray pattern allows concluding that the features of the orange and yellow nozzles coincide within the error taking into account the difference in the values of the working fluid flow rate.

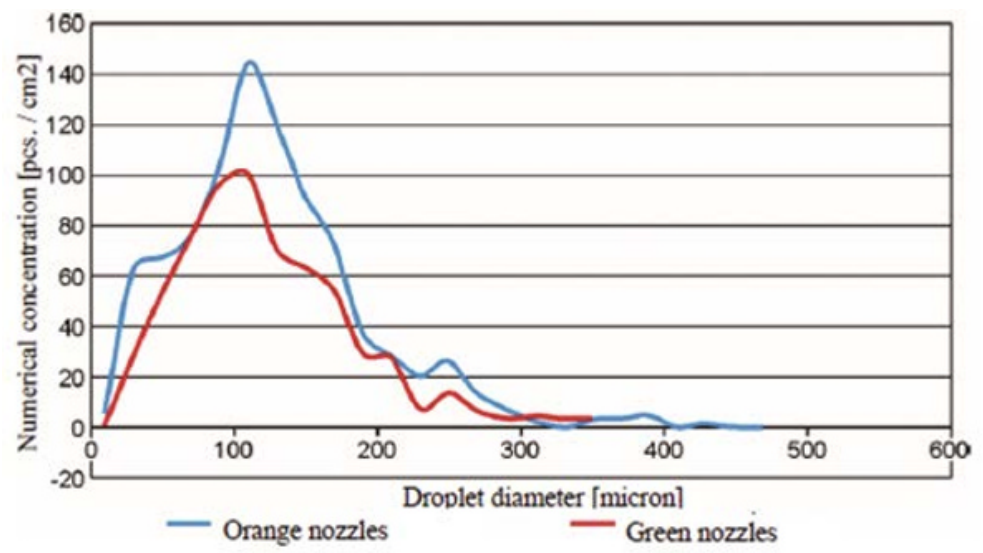

Fig. 5. Drop size distribution chart.

The performed experiments showed the corresponding technological capabilities of the experimental measuring facilities during comparative tests of sprayers. Creation of a technology for practical testing of sprayers based on the experimental facilities will make it possible to identify and scientifically substantiate theoretical laws, rules, methods for calculating and controlling industrial aerosols, and ultimately, to form incoming control over the quality of nozzles supplied to the domestic market [2].

\section{References}

1. Fedorenko, V.F., Aristov, E.G., Krakhovetsky, N.N., Selivanov, V.G. (2019) A method of determining the size of the drops. Patent No. 2709402.

2. Veretennikov, Yu.M., Paremsky, I.Ya., Ovsyankina, A.V. (2008) A new scientific and technical area in the physics of dispersion fluid systems Tractors and agricultural machines $\mathbf{8}$. 